\title{
HERITAGE
}

\section{On Ancient Astronomy in Armenia}

\author{
E.S. Parsamian
}

NAS RA V. Ambartsumian Byurakan Astrophysical Observatory (BAO)

E-mail:elma@sci.am

\section{Introduction}

The Armenian highland is one of the ancient cradles of civilization. Many investigators of the history of astronomy, having no facts to hand, mainly by logical approach came to the conclusion that the ancient inhabitants of Armenia not only knew, but also took part in the formation of ancient astronomy (Maunder, 1906; Olcott, 1914).

Thus, Olcott wrote: "Astronomical facts correspond with historical and archaeological investigations and prove that people who have invented the ancient figures of constellations probably lived in the valley of the Euphrates, as well as in the region near the mountain Ararat".

Maunder, investigating the issue of the origin of the constellations, wrote: "People, who divided the sky into constellations, most probably lived between 36 and 42 degrees of the northern latitude, so neither Egypt nor Babylon could be the motherland of creation of constellations. Calculating in what place the center of this empty region coincides with the North Pole, we got the figure $2800 \mathrm{BC}$, which is probably the date during which the naming of the constellations were completed. It was observed that such animals as the elephant, camel, hippopotamus, crocodile and tiger were not amongst the figures representing the constellations, there, fore we can assert India, Arabia, and Egypt could not have been the place where the idea of firmamen originated.

We can exclude Greece, Italy and Spain on the basis of the fact that the figure of lion is present in the figures of constellations. Thus, purely by logical thinking we can assert that the motherland of celestial figures must be Minor Asia and Armenia, that is to say a region limited by the Black, the Mediterranean, the Caspian and the Aegean Seas."

The above statements had to be confirmed. The discoveries made during the last decades in Armenia, have enriched our knowledge of the ancient civilization and 
ancient astronomy in this region.

On Armenian territory, a belt calendar and geocentric model of the universe were discovered from the Bronze Era, dating back to the XI century BC (Tumanian and Mnazakanian, 1965). Furthermore, rock carvings of astronomical representations of the Sagittarius, Lion, and Scorpio constellations, along with symbols of the Sunand the Moon, were discovered on fragments of rocks older than 3000 years. The diameters of the pictures are different from each other, indicating the relative brightness of the stars. On one fragment the Sun, Moon, and five planets, as seen with the naked eye are pictured, and on the other two fragments, there are circles with short and 29 long rays. The rays carved on the rocks probably depict the period of repetition of the lunar phases.

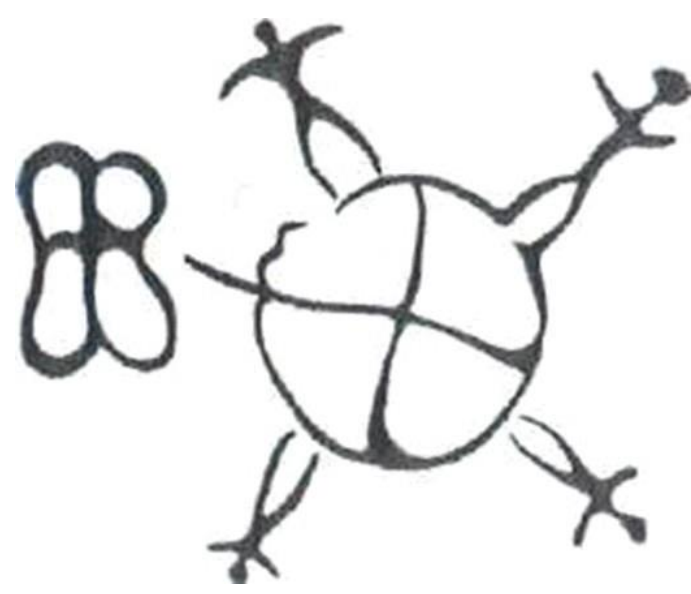

Figure1. Image of Earth with the antipodes found on rocks

A carved circle found on one of the rocks create agreat deal of interest. This circle is divided by orthogonal lines, in which (on opposing sides) area I so carved human figures. These symbols represent the Earth and antipodes on it (Fig.1). Such symbolism is also used in modern astronomy (Tumanian \& Petrosian, 1970).

\section{The ancient "Observatory" of Metsamor}

The important discovery, which enriched our knowledge of ancient astronomy in Armenia, were the complex of platforms for astronomical observations on the Small Hill of Metsamor, which may be called an ancient "observatory". Investigations of that Hill show that the ancient inhabitants of the Armenian Highlands have left for us not only pictures of celestial bodies, but also a very ancient complex of platforms for observing the sky. On the bank of the river Metsamor, some $30 \mathrm{~km}$ west of Yerevan, a metal-producing center was found, dating back to the third millennium BC. The life 
here dated from $V$ millennium $B C$ up to XVIII century AD.

Here on the Small Hill of Metsamor in 1966 the platforms for astronomical observations were discovered, which form a peculiar complex - an ancient "observatory" (Parsamian \& Mkrtchian, 1969; Parsamian, 1985a; Parsamian,1988).

Of the platforms, three are particularly well preserved. The first (Fig.2) is triangular in shape, with its smallest angle facing the South. The bisector of that angle coincides with the North-South direction (with an accuracy of 2 degrees). On the rock surfaces a number of symbols are carved. These symbols and images are sometimes also repeated on the other rocks as well.

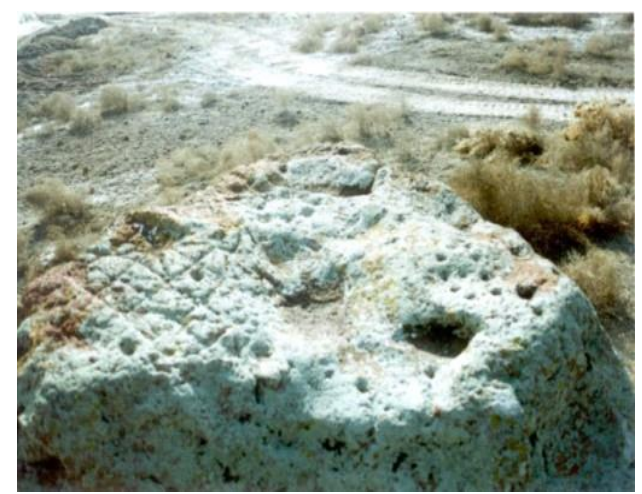

Figure2. The first platform with stellar symbols on the eastside

On the east side of the first platform, there are four identical stellar symbols surrounded by a trapezium measuring $55 \times 40 \mathrm{~cm}$. Of these four symbols, three are particularly well preserved. This trapezium is drawn narrower in the south-east; a choice of geometry which is not accidental, as will be revealed later.

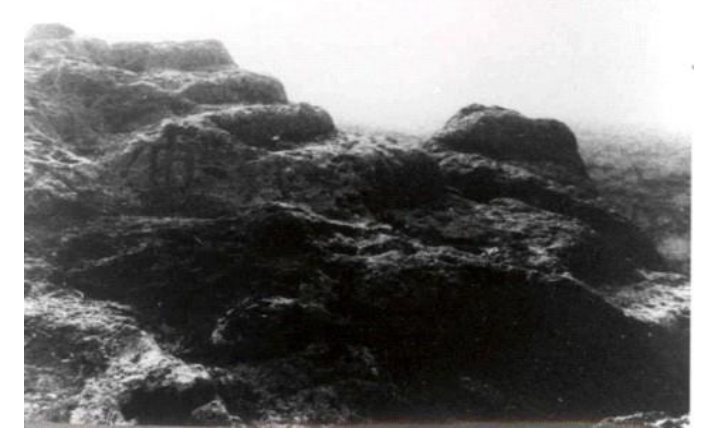

Figure 3.The third platform with seven steps

One might assume that the center of the platform might be a good place to place the symbols. However, the positioning of the trapezium and the symbols may be the key to its secrets. The very fact that the trapezium with the star symbols is carved on the eastern side suggests the idea that it is connected with the rising of some star or the Sun. The Sun however can be excluded, as it used to have its own 
unique symbol in ancient times. The question now is which heavenly body was the trapezium pointing to?

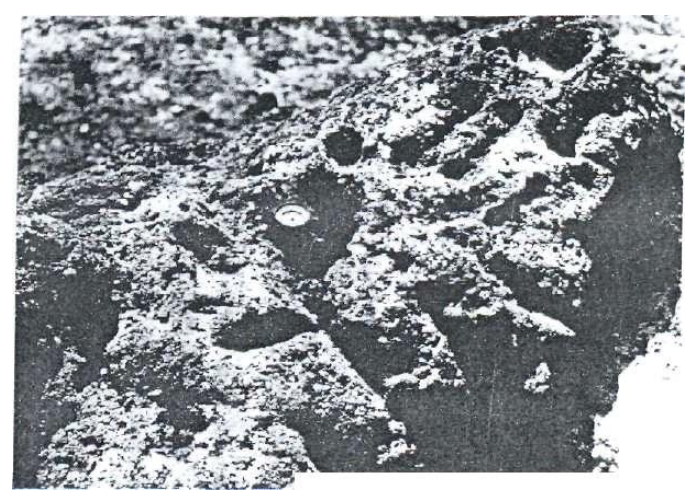

Figure 4. A carved directional indicator (compass) is on the top of the third plat-form. It indicates north-south-east directions

Table 1

\begin{tabular}{|c|c|c|}
\hline \hline Star & Mag & epoch \\
\hline Sirius & -1.58 & -2600 \\
Rigel & 0.34 & -2100 \\
Antares & 1.22 & 400 \\
$\beta$ CMa & 1.99 & -1000 \\
\hline
\end{tabular}

Let us continue mentally the altitude of the trapezium up to the horizon and see with the rising of what heavenly bodies this direction is connected. We measured the azimuth of the trapezium with a compass and made some calculations. Let $\mathrm{A}$ be the azimuth of the carved altitude of the trapezium dividing it into two equal part, (the line of the altitude is preserved but it is drawn roughly, so an error of measurements of the azimuth of the trapezium gave the value $A=295^{\circ}$. The value of declination was found to be $-21^{\circ}$, the value of an hour angle $t-71^{\circ}$. From these data it is not difficult to establish what bright stars had the mentioned above declination and when. According to 5000 year star catalogue (Hawkins and Rosenthal, 1967) the Table 1 gives then am off our brightest stars, their brightness, as well as the epoch, where declination was equal to $-21^{\circ}$ there are four candidates: Sirius, Rigel, Antares, $\beta C M a$.

Most probably, Sirius was observed and worshipped by the ancient in habitants of Metsamor, and the information they left concerns this star. Table 2 gives the results of calculations for the rising of Sirius in Metsamor at summer Solstice; we indicate the epoch for three different values of azimuth $\left(A=298^{\circ}\right.$ being the most probable value). 
Table 2

\begin{tabular}{|c|c|c|c|}
\hline \hline Azimuth & Decl. & Localtime & Epoch \\
\hline 300 & -22.20 & $4 \mathrm{~h} \mathrm{39m}$ & -2800 \\
298 & -22.55 & $4 \mathrm{~h} 43 \mathrm{~m}$ & -2600 \\
296 & 19.00 & $5 \mathrm{~h} \mathrm{03m}$ & -1900 \\
\hline
\end{tabular}

It was shown that in the years between 2800-2600 BC Sirius could have been observed at Solstice in the morning, in the rays of the rising Sun, this being the socalled helical rising of Sirius. It is obvious from the data that Sirius, the brightest star in our hemisphere could have been the object of worship by the inhabitants of Metsamor. It is possible that, like the ancient Egyptians, the inhabitants of Metsamor related the first appearance of Sirius with the opening of the year.

The occurrence of the symbol for Sirius four times in the trapezium can be explained by the fact that, as in the Egyptian calendar, where the year had 365 days, after every 4 years the rising of Sirius was shifted from the first day to the second day of the month, and after another 4 years from the 3rd day to the 4th and so on. If these suppositions are correct, then the findings on the first platform prove that the inhabitants of Armenia were well acquainted with the sky, and could have used the periodical appearance for measuring time.

The second platform is situated $2.5 \mathrm{~m}$ above the first one. It is also triangular and in the plane of meridian. The sign of the Sun and other signs are there.

Of special interest is the third platform (Fig.3). It differs from the other two in having seven steps carved in the rock, which lead in from a North-South direction. These steps are positioned roughly in the plane of the meridian. If the stairs leading to the platform were in the East-West direction, then one might assume that the platform was being used for religious ceremonies. The stairs however were positioned in the North-South direction, which provided an optimum position for carrying out astronomical observations. On the last stepleading to the platform, a carved directional indicator (compass) was made which shows North-South-East directions (Fig.4). The presence of the compass suggests that the platform was not positioned exactly on the meridian plane and this compass had to be use to correct the position of the observer. The other carved signs found on the hills and the platforms also lead us to understand that the platforms, as well as serving as astronomical observation platforms, could also be used for religious rituals.

However, for religious rituals on the Main Hill of Metsamor was found Pagan Altar situated in the plane east-west from the first millennium BC. 


\section{Megalithic Monument Zorats Kar}

Among the ancient monuments in Armenia there is a megalithic monument, probably, being connected with astronomy. $250 \mathrm{~km}$ south-east of Yerevan there is a structure Zorats Kar (Fig. 5) dating back to II millennium BC. Vertical megaliths many of which are more than two meter so height form stone rings resembling the ancients tone monuments-henges in Great Britain and Brittany (Parsamian, 1985b; Parsamian and Barsegian, 1987; Geruni, 1998).

The diameter of the main stone ring of Zorats Kar is more than $30 \mathrm{~m}$ and it is notable that on some stones found in the eastern part there are well polished round holes, which could have been used for the observation of the Sun in the days of equinox and solstice. The main ring is connected with megaliths in S-E direction by gate of two megaliths the distance between which is more than between other stones. The first observations of the sunrise the days of solstice shows that the middle line of gate has direction East- West. On the direction N-E from the gate there is a range of nine megaliths. Sunrise observations on June22, 1985 showed the Sun appearance from the gate on the top of highest megalith at the moment of sunrise. In the same moment, it was possible to see Sun in the holes of two megaliths N 39 and $\mathrm{N} 44$. Numeration of the holes was begin from north end of stone avenue, which leads to main stone ring in the N-S direction. After short time during sunrise, Sun was seen through first megalith's hole from the gate. During the observations of sun rise on 21 September, 1985 before appearance of Sun in the middle of gate we observed Venus. We suggested that the place of gate was chosen for observations of periodic events (Parsamian, 1985b; Parsamian and Barsegian, 1987).

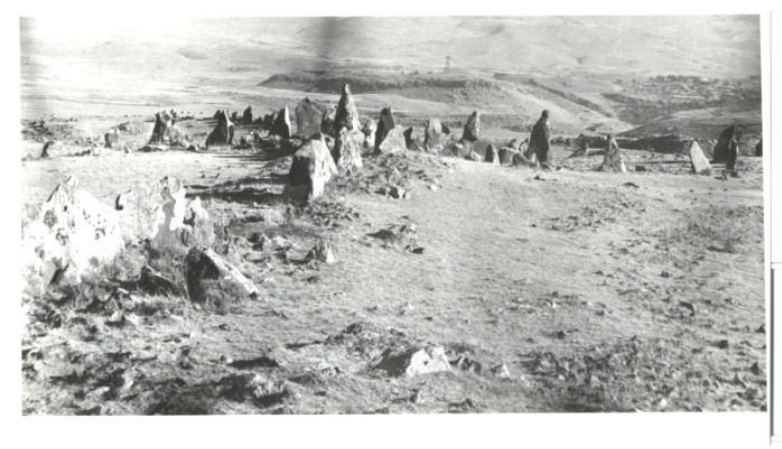

Figure 5.ZorazKar

In the same region, about $40 \mathrm{~km}$ from Zoraz Kar there is located the village Karahunge, the name of which give us some information to meditate. Kharahunge is a compound word in which the part "Kar" means stone and "hunge" likely means bouquet: there is not such word in Armenian dictionary (Parsamian, 1985b). 
According to hypothesis of Gamkrelidze and Ivanov (1990) the Indo-European languages were originated on the eastern Anatolia which is historical homeland of Armenians.

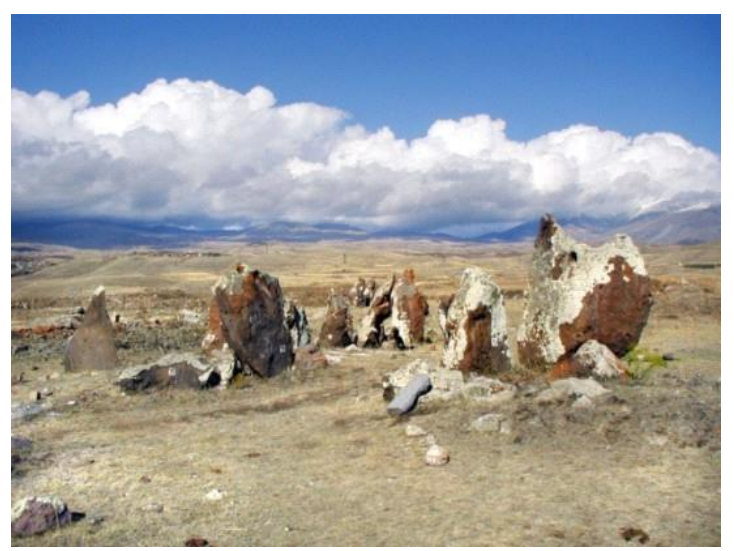

Figure 6.ZorazKar

\section{Medieval Observations of Comets and Novae by Data in Ancient Armenian}

In the collection of ancient Armenian manuscripts (Matenadaran) in Yerevan there are many manuscripts with information about observations of such astronomical events in medieval Armenia as solar and lunar eclipses, comets and novae, bolides and meteorites etc. In particular, there is interesting information about observations of super-novae in 1006, 1054, possible supernova in 716, two novae in 762 (Astapovich 1974; Tumanian 1964; Barsegian and Parsamian,1990).

Up to nowadays,75 informative facts about appearances of 60 comets are found in Armenian medieval sources (Vsekhsvyatskij and Tumanian,1970; Barsegian and Epremian, 1989). In particular, Halley's comet was observed from Armenia in 684, 989, 1066, 1222, 1145, and 1531 (Brutian, 1998; Barsegia and Epremian, 1989; Barsegian and Parsamian, 1998).

\section{References}

Astapovich, Is., 1974, Astron. Zirk., AN SSSR, 826.

Barsegian, A.J., Epremian, R.A., 1989, Soobsch. Byurakan Obs., 61.

Barsegian, A.J., Parsamian, E.S., 1990, Soobsch. Byurakan Obs., 63, 92.

Barsegian, A.J., Parsamian, E.S., 1998, Proceedings of Armpedinstitute, 49.

Brutian,G. H., 1998, private communication.

Gamkrelidze,T. V., Ivanov, V.V.1990, V Mire Nauki, 5, 660. 
Geruni, P. 1998, Dokl. NAN of Armenia, 98, 307.

Hawkins G.S., Rosenthal, Sh.K., Smithsonian Contributions to Astrophysics, Vol.10, N2.

Maunder, E., 1906, Astronomy without Telescopes, London.

Olcott, W. 1994, Legends of Stellar Universe, Petersburg.

Parsamian,E.S., Mkrtchian,K.A. 1969, Historic-Astronomical Investigations, $X, 35$, Moscow.

Parsamian, E. S., 1985a, Soobsch. Byurakan Observatory, 57, 92.

Parsamian, E. S., 1985b, Soobsch. Byurakan Observatory, 57, 101.

Parsamian E. S., Barsegian A. J., 1987, Some Questions of Experimental Physics, Proceedings of Armpedinstitut, 58, Yerevan.

Parsamian,E. S., 1988, Historic and Astronomical Investigations, XX, 139, Moscow.

Tumanian, B. E., 1964, History of Armenian Astronomy, 1, 141.

Tumanian, B. E., Mnazakanian, A.O., 1965, Belt Calendar of the Bronze Age, Yerevan.

Tumanian, B. E., Petrosian,S. B., 1970, Uchen.Zapis. of Yerevan Univ., 1, 16. Vsekhsvyatskij, S.K., Tumanian,B. E. 1970, Uchen. Zapis. of Yerevan Univ., 3, 52. 